\title{
Intermixed Dimethyl-Sulfoxide-Based Nonadhesive Liquid Embolic Agents Delivered Serially via the Same Microcatheter for Cerebral AVM Treatment
}

\author{
(D) A. Sirakov, (D) K. Minkin, and (D) S. Sirakov
}

\begin{abstract}
BACKGROUND AND PURPOSE: Conventional nonadhesive liquid embolic agents currently are the criterion standard for endovascular embolization of cerebral AVMs. However, inadequate distal penetration into the nidus and unstable proximal plug formation are the major limitations of this approach and of the currently available embolic materials. The aim of this study was to evaluate the hypothetic efficacy of combining liquid embolic agents with different properties and viscosities for use in endovascular embolization of cerebral AVMs.
\end{abstract}

MATERIALS AND METHODS: From March 2018 to March 2019, sixteen patients with cerebral AVMs (12 women, 4 men; age range, 33-61 years) underwent endovascular embolization with combined liquid embolic agents delivered serially via a single microcatheter. The procedure consists of initial embolization with PHIL 30\%, followed by Menox 18 through the same microcatheter. According to the Spetzler-Martin scale, 11 (68.75\%) AVMs were grades I-II, 4 (25\%) were grade III, and 1 (6.25\%) was grade IV. Angiographic, technical, and clinical outcomes were analyzed independently.

RESULTS: Combined PHIL and Menox embolization through the same microcatheter via 21 pedicles was performed in these 16 patients. Once the length of the reflux reached approximately $2 \mathrm{~cm}$, PHIL $30 \%$ was switched to Menox 18. Antegrade flow and distal penetration of the serially applied liquid embolic agents were observed in all 16 cases. The ability to completely control the flow of the materials and avoid any dangerous proximal reflux was noted in all performed embolizations. The estimated average size reduction of the treated AVMs was $85 \%$, ranging from $50 \%$ to $100 \%$. Complete embolization was achieved in $10 / 16$ or $62.5 \%$ of the cases. There was no procedure-related complication during or after the embolization. No mortality or postprocedural clinical worsening was seen. Clinical success and complete obliteration were confirmed with at least 1 follow-up angiography in 10/16 patients.

CONCLUSIONS: Serial delivery of nonadhesive liquid embolic agents via the same microcatheter was safe and effective in our study and may be a potential technique for routine AVM treatment. However, further investigations are required to validate the safety and the efficacy of the method.

ABBREVIATIONS: DMSO = dimethyl-sulfoxide; EVOH = ethylene-vinyl alcohol copolymer; LEA = liquid embolic agent

iquid embolic agents are primarily used for treatment of cerebral AVMs. ${ }^{1}$ The most widely used liquid embolic agents are the nonadhesive ethylene-vinyl alcohol copolymers (EVOHs): Onyx (Covidien, Irvine, California), SQUID (Emboflu, Gland, Switzerland), Menox (Meril Life Sciences, Gujarat India), and polyhydroxyethylmethacrylate copolymerPrecipitating Hydrophobic Injectable Liquid (PHIL; MicroVention, Tustin, California), along with the well-known $n$-BCA. ${ }^{2-4}$ The major

Received November 5, 2019; accepted after revision January 10, 2020.

From the Radiology Department (A.S., S.S.) and Neurosurgery Department (K.M.), UH St Ivan Rilski, Sofia, Bulgaria

Please address correspondence to Stanimir Sirakov, MD, PhD, UH St Ivan Rilski, 15 Academic Ivan Geshov boulevard, Sofia, Bulgaria; e-mail: ssirakov@bsunivers.com; @AlexanderSirak1

http://dx.doi.org/10.3174/ajnr.A6453 limitation of the conventional EVOH embolization technique is that on some occasions, it is difficult to control the reflux of the material at the level of microcatheter tip and the formation of a stable proximal plug. Establishing a stable proximal plug is crucial because it allows better distal antegrade nidal penetration. Technically speaking, EVOHs with extra-low viscosity could improve the distal penetration of the embolic agent. Currently, the only commercially available extra-low-viscosity formulation of EVOH is SQUID $12 .^{5}$

Initial experience with the recently introduced liquid embolic agent PHIL has shown that this agent may, due to its intrinsic properties, address the limitation of its nonadhesive EVOH competitors in terms of proximal plug formation. ${ }^{6}$

We sought to explore whether 2 different, serially applied nonadhesive liquid embolic agents via the same microcatheter 
could increase the embolization success rate of cerebral AVMs. We hypothesized that using liquid embolic agents with different properties and viscosities could improve the AVM embolization with less proximal reflux. The technical aspects of this approach were evaluated as were immediate clinical and angiographic results.

\section{MATERIALS AND METHODS}

The study protocol was reviewed and approved according to the local institutional policy, and appropriate consent was obtained from each patient. From March 2018 to March 2019, in a singlecenter institution, a total of 16 patients with cerebral AVMs underwent endovascular embolization with combined liquid embolic agents (LEAs) serially delivered via a single microcatheter. All patient demographics, AVM angioarchitecture, procedural details, pre- and postprocedural mRS scores, and clinical data were collected (Table 1). The study population consisted of 12 women and 4 men, with ages ranging from 33 to 61 years. The most common clinical presentation was hemorrhage in $75 \%$ of patients (12/16), with the remaining 25\% (4/16) presenting with headaches and epileptic seizures. Based on the size, eloquence, and venous drainage of the lesions per the Spetzler-Martin scale, $11(68.75 \%)$ AVMs were grades I-II, 4 (25\%) were grade III, and $1(6.25 \%)$ was grade IV. Low-grade AVMs (Spetzler-Martin grades I and II) were intended to be definitively treated, while staged endovascular embolization was planned for larger AVMs, rendering them suitable for subsequent microsurgical resection. None of the included patients had any previous microsurgical or endovascular treatment.

\section{Description of the Technique}

All procedures were performed with the patient under general anesthesia in a dedicated neuroangiography suite. During the procedures, systolic blood pressure was maintained between 80 and $100 \mathrm{~mm} \mathrm{Hg}$ to prevent any possible migration of embolic material to the venous compartment of the AVM. Catheterization of the right distal radial artery was performed in all 16 patients. A 6F guiding catheter was then introduced into the appropriate feeding artery over an exchange-length wire using standard techniques. The choice of arterial feeders most suitable for intermixed embolization was made by the treating physician on a case-by-case basis. Dimethyl-sulfoxide (DMSO)compatible Apollo microcatheters (Covidien) were delivered over a 0.010- or 0.008-inch microwire into the selected feeding pedicle and its desired segment with the tip positioned as close as possible to the nidus of the AVM. The hub lumen and the dead space of the microcatheter were then primed with $0.25 \mathrm{~mL}$ of DMSO.

The basis of the embolization technique was to first perform primary injections with PHIL $30 \%$ to optimize the initial plug formation. As soon as the length of injected PHIL reached $1.5 \mathrm{~cm}$ or was close to the proximal marker of the microcatheter, Menox 18 was applied as a second embolic agent via the same microcatheter. Additional DMSO was not injected between applications of the 2 liquid embolic agents. Because a solid proximal plug was already formed, Menox, due to its different intrinsic properties, was able to penetrate more distally and thus achieve an optimized AVM embolization via the same microcatheter. On completion
Table 1: Baseline characteristics of the treated patients

\begin{tabular}{|c|c|}
\hline Variable & Value \\
\hline \multicolumn{2}{|l|}{ Age $(y r)$} \\
\hline Mean & 33.5 \\
\hline Median & 42 \\
\hline Range & $33-61$ \\
\hline \multicolumn{2}{|l|}{ Sex (No.) (\%) } \\
\hline Male & $25 \%(4)$ \\
\hline Female & $75 \%(12)$ \\
\hline \multicolumn{2}{|l|}{ Presentation (No.) (\%) } \\
\hline Hemorrhage & $75 \%(12)$ \\
\hline Neurologic deficit & - \\
\hline Headache & $12.5 \%(2)$ \\
\hline Epilepsy & $12.5 \%(2)$ \\
\hline Asymptomatic & - \\
\hline \multicolumn{2}{|l|}{ Size (\%) (No.) } \\
\hline$\leq 30 \mathrm{~mm}$ & $75 \%(12)$ \\
\hline$\geq 30 \mathrm{~mm}$ & $25 \%(4)$ \\
\hline \multicolumn{2}{|l|}{ No. of arterial feeders (\%) } \\
\hline Single & $43.7 \%(7)$ \\
\hline Multiple & $56.3 \%(9)$ \\
\hline \multicolumn{2}{|l|}{ Venous pattern (No.) (\%) } \\
\hline Superficial & $68.7 \%(11)$ \\
\hline Deep & $18.7 \%(3)$ \\
\hline Deep and superficial & $12.5 \%(2)$ \\
\hline \multicolumn{2}{|l|}{ Spetzler-Martin score } \\
\hline 1 & $31.2 \%(5)$ \\
\hline II & $37.5 \%(6)$ \\
\hline III & $25 \%(4)$ \\
\hline IV & $6.3 \%(1)$ \\
\hline \multicolumn{2}{|c|}{ mRS prior to embolization } \\
\hline 1 & $68.7 \%$ (11) \\
\hline 2 & $25 \%(4)$ \\
\hline 3 & $6.3 \%(1)$ \\
\hline
\end{tabular}

of the endovascular embolization, control contrast injections were performed through the guide catheter and the microcatheter was subsequently removed from the pedicle under fluoroscopy. This technique was performed in all cases (Fig 1). No pressurecooker technique or any other antireflux modifications were used in this cohort. ${ }^{7}$

At the end of each embolization session and for each microcatheter used, the amount of traction force required to successfully retrieve the catheter was individually assessed. The perceived difficulty (eg, easy, moderate, strong) was subjectively documented by the main operator following every microcatheter removal.

Distal detachable tips of the microcatheters used were carefully examined under stereomicroscopy for any evidence of adherent or mixed embolic material fragments.

Angiographic results were determined by estimating the percentage of nidus reduction observed in the last intraprocedural angiogram. All angiograms were blindly and independently reviewed by 2 outside interventionists. Final verdict and complete interpretation of the data were reached through a consensus session.

\section{Study Outcome Measures}

As per our institutional routine protocol, the first follow-up with DSA combined with clinical evaluation was performed 6 months 


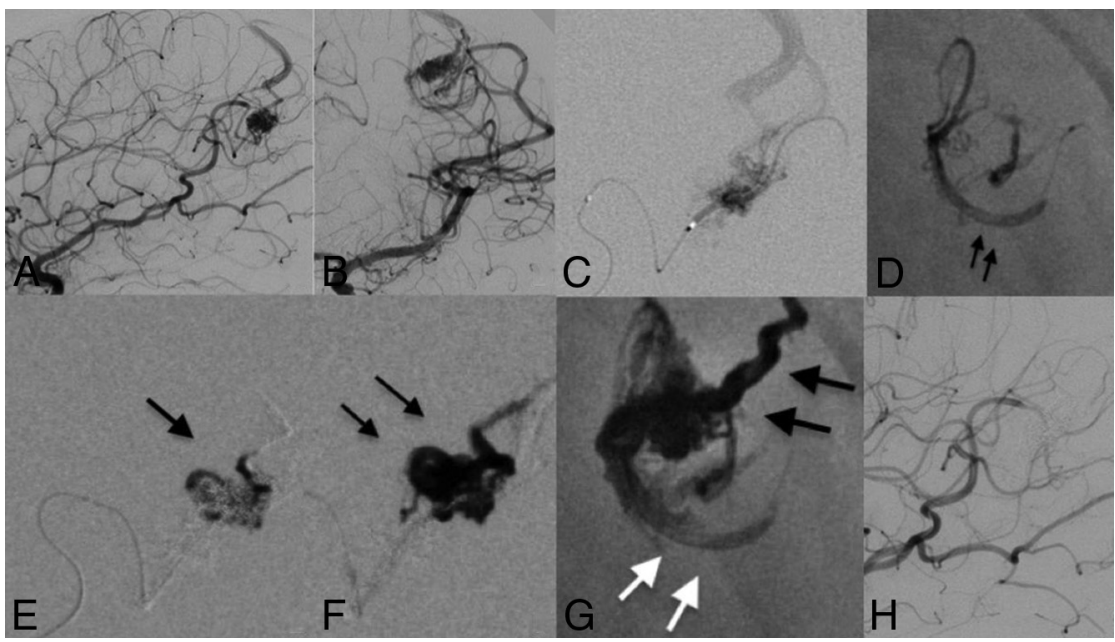

FIG 1. A 35-year-old female patient who presented with left-sided headache and seizures. DSA revealed a left parietal $(A$ and $B)$ AVM supplied by the left MCA. The AVM was drained by the superficial cortical vein to the superior sagittal sinus. An Apollo microcatheter was positioned into a distal arterial feeder arising from the left MCA (C). A PHIL 30 plug was created with 2 rounds of injections ( $D$, arrows). After $1.2 \mathrm{~mL}$ of PHIL 30 was injected into the AVM, embolization was continued with Menox 18 ( $E$ and $F$ ) to ensure successful distal and continuous penetration. No further proximal reflux was observed $(G)$. Note the different radiopacities of the used liquid embolic agents (black arrows, Menox 18; white arrows, PHIL 30.) At the end of the procedure, $100 \%$ size reduction was achieved by delivering a total amount of $2.7 \mathrm{~mL}$ of embolic material from 1 feeder during 1 session $(H)$.

Table 2: Embolization characteristics and technical results ${ }^{a}$

\begin{tabular}{|c|c|c|}
\hline Study Group $(n=16)$ & \multicolumn{2}{|c|}{ Value } \\
\hline Applied LEA & PHIL 30 & Menox 18 \\
\hline Total fluoroscopy time (sec) & \multicolumn{2}{|c|}{$2460(900-3761)$} \\
\hline Total injection time (sec) & $55(51-70)$ & $325(480-980)$ \\
\hline Time per single injection (sec) & $5.8(6.6-12.1)$ & $21.1(12-50.1)$ \\
\hline Injection pause time (sec) & $0.4(1.1-2.2)$ & $1.1(0.4-30)$ \\
\hline Injections (No.) & $4.1(2-5)$ & $11(8-35)$ \\
\hline $\begin{array}{l}\text { Total volume of LEA per } \\
\text { procedure }(\mathrm{mL})\end{array}$ & $0.9(0.7-2.3)$ & $4.1(1.2-6)$ \\
\hline
\end{tabular}

${ }^{a}$ Data are presented as median (lower quartile; upper quartile).

after the treatment. A cranial MR imaging and clinical assessment were performed on discharge after each endovascular session and on each follow-up if considered mandatory. The neurologic examination was performed by a neurologist or a certified stroke nurse and recorded using the mRS.

\section{Primary End Points}

The primary end points were complete nidal occlusion of Spetzler-Martin grade I-II AVMs, with the rate of favorable clinical outcomes defined as mRS 0-2 at 30 days after embolization.

\section{Secondary End Points}

Secondary outcomes included either intraprocedural or postprocedural intervention-related complications leading to permanent neurologic deficits. Other secondary outcomes included parent vessel injury, extravasation of the applied LEAs, rerupture of the AVM, the degree of the nidal obliteration, and the occurrence of intervention-related stroke or death. Technical complications were defined as unsuccessful microcatheter retrieval, microcatheter occlusion, and any adverse physiologic changes due to the combination of both agents.

\section{RESULTS}

Combined PHIL and Menox embolization was performed in all 16 patients. Fast and solid proximal plug formation was achieved in all cases via initial applications of PHIL 30\%. Proximal plug formation with PHIL 30\% was performed without difficulty in 21 pedicles, and the embolization proceeded accordingly. Successful and continuous application of the second embolic agent, Menox 18, was performed in all patients. Antegrade flow of the EVOH material into the nidal components was observed in all 16 cases. The mean volume of PHIL used was $0.9 \mathrm{~mL}$ (range, 0.7$2.3 \mathrm{~mL}$ ), and the mean volume of $\mathrm{EVOH}$ injected was $4.1 \mathrm{~mL}$ (range, $1.2-6 \mathrm{~mL}$ ). We noted mean injections pause times of 0.4 seconds for the PHIL and 1.1 seconds for the EVOH with a mean time under fluoroscopy of just 41 minutes per procedure. Technical results are summarized in Table 2.

No microcatheter remained irreversibly trapped in the plug, and no technical complications such as microcatheter occlusion or rapid tantalum sedimentation occurred. Six detachable distal tips of the used microcatheters were successfully retrieved. Among those 6 microcatheters, in 2 of them, adherent microscopic particles of the liquid embolic cast and structural crack scratches were noted over the most distal portion of the tip.

No adverse physiologic changes such as vessel injury, embolic agent extravasation, or microcatheter rupture were observed.

\section{Angiographic Outcomes and Follow-Up Examinations}

AVM volume was calculated using the method of Pasqualin et al. ${ }^{8}$ Adequate nidal penetration was achieved in all cases. The estimated average size reduction of the treated AVMs was $85 \%$, ranging from $50 \%$ to $100 \%$. We achieved complete angiographic obliteration of the nidus in 10/16 (62.5\%) patients after the initial session with serially combined LEAs, all of whom had small AVMs (Spetzler-Martin grade I or II) (Fig 2). Favorable clinical outcome and complete obliteration were confirmed with at least 1 follow-up angiography after a mean of 5.1 months (range, 36 months) in each of the 10 patients.

Partial embolization was achieved in 6/16 (37.5\%) patients. One of those patients underwent microsurgical resection of the nidus due to enlargement of the intraparenchymal hematoma that was present during radiologic examination at admission.

Planned embolization via the same method was performed for the remaining 5/16 (31.25\%) patients to achieve sufficient 


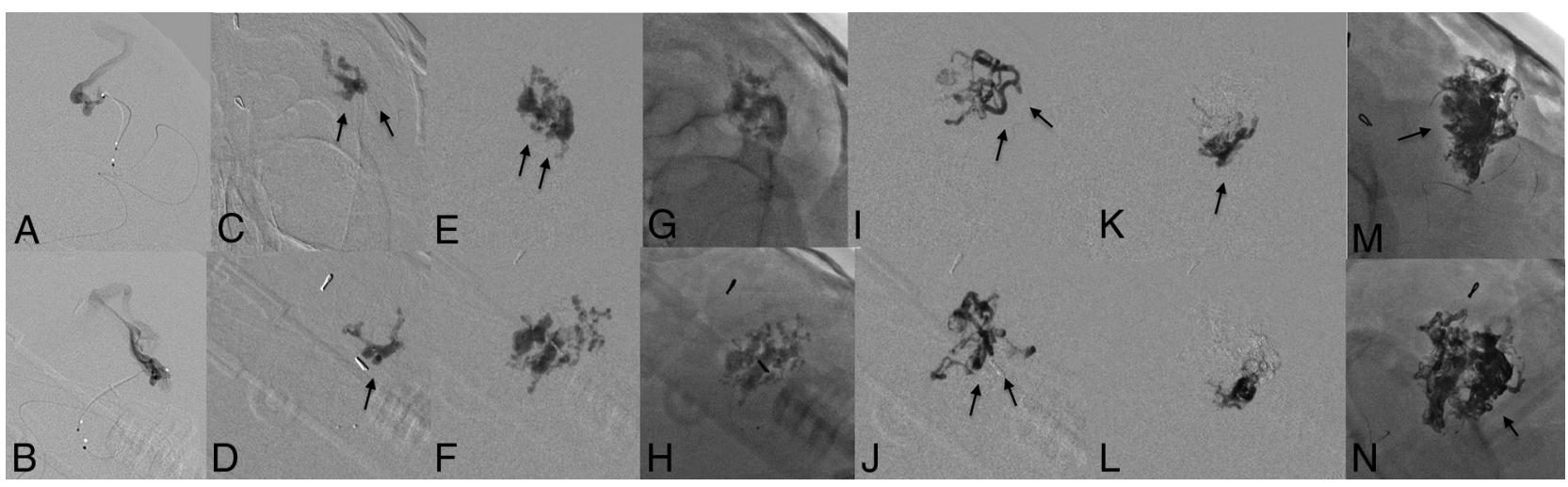

FIG 2. Step-by-step embolization of a ruptured left-sided parietal AVM, Spetzler-Martin grade II. The tip of the microcatheter was placed into the nidus ( $A$ and $B$ ). Initial injections of PHIL 30 (C, D, E, F, G, and $H$; arrows) were needed to create a stable proximal plug. The embolic material was switched with Menox 18 to successfully achieve distal and continuous nidal penetration (I-L; arrows). Note the distal extent of the Menox agent $(M, N$, arrow) and the different radio-opacities of the applied LEAs.

AVM nidal occlusion suitable for subsequent radiosurgery or surgical resection.

There was no procedure-related complication during or after the embolization. No mortality or worsening mRS postprocedurally was seen in this cohort.

\section{DISCUSSION}

Today, dimethyl-sulfoxide-based nonadhesive embolic agents are the main tool used for the multimodality treatment of cerebral AVMs. ${ }^{9}$ EVOH was pioneered in the neurointerventional field and quickly became proclaimed the criterion standard for curative AVM embolization. ${ }^{10}$ This liquid embolic material is thought to be an easily manageable agent. Its greatest advantage of slowly controllable embolization and the ability to initiate and interrupt injections may reduce the risk of any dangerous migration of the embolic mass. However, the major limitation of $\mathrm{EVOH}$ is that its nonadhesive nature limits control over the direction of polymer flow and can lead to excessive reflux, which may result in incomplete nidal embolization or dangerous proximal backflow and obstruction of normal arterial feeders. Usually, this issue can be addressed by intentionally allowing the agent to cover a small portion of the detachable tip of the microcatheter, creating a proximal "plug." ${ }^{\text {"11 }}$ This process often requires multiple short cycles of repeat injections, thereby increasing the total duration of the procedure as well as the risk of vessel rupture or rapid tantalum sedimentation inside the microcatheter. ${ }^{12}$ The waiting time between applications of the agent to ensure an appropriate degree of hardening of the LEA is important because not waiting long enough can lead to premature embolization of the feeding artery. On the other hand, the flow pattern through the nidus can be somehow redirected by allowing the already-injected material to harden and thus creating a new low-resistance channel. ${ }^{13}$ All of these shortcomings are associated with the effect of the plug and properties of the $\mathrm{EVOH}$ technique.

The polylactide-co-glycolide and polyhydroxyethylmethacrylate copolymer PHIL is a nonadhesive and inherently radio-opaque LEA. Initial experience with this agent has revealed the potential advantages of this LEA over the standard EVOH technique. Reported differences include the ability to create a faster and stable proximal plug, a constant degree of distal nidal penetration, and consistent visibility due to the presence of iodine as its radioopacity component. The material is available in 3 different concentrations and viscosities: PHIL 25, 30, and 35. Higher concentrations are preferred in the presence of a fistulous component, whereas lower concentrations are used to achieve better distal penetration. It has already been demonstrated that the successful outcome of embolization can be based on the effect of the proximal plug and the viscosity of the material used..$^{14,15}$

Both Menox 18 and PHIL are DMSO-based liquid embolic agents that require DMSO-compatible microcatheters to enable a safe and efficient embolization process. Special emphasis is placed on the need for deliberation when choosing the most appropriate embolic material. Depending on the specific angioarchitecture and the geometry of the feeding arteries, use or even the combination of liquid embolic agents is often required. In our experience, combined injections of PHIL and Menox via the same microcatheter have been technically possible and safe, offering the advantage of switching between agents without the additional application of DMSO. The lesser layering effect and higher viscosity of PHIL 30 offer better properties of the proximal plug, thus ensuring successful distal penetration of Menox 18, which has 50\% lower viscosity (36 cSt, PHIL 30, versus $18 \mathrm{cSt}$, Menox 18). More specifically, the initial injection of PHIL 30 creates a proximal stop that successfully blocks the flow and creates a distinctive change in the pressure gradient within the nidus, thus supporting the forward, more distal penetration of Menox due to its lower viscosity. We believe this may limit potentially dangerous proximal backflow and decrease the amount of embolic agent used. We noted a mean time under fluoroscopy of only 41 minutes and relatively shorter EVOH pause times.

From our routinely collected data, we performed direct comparisons among the Menox or PHIL infiltration times using this approach versus the conventional method. The reported injection pause times and the mean fluoroscopy times were relatively shorter than those we observe on a daily basis in comparison with injections of EVOH or PHIL as stand-alone liquid embolic agents. ${ }^{16,17}$ However, direct head-to-head comparison is difficult 
to perform with great accuracy because each AVM has distinct anatomic and flow characteristics.

Serial application of EVOH and PHIL via the same microcatheter was reported by Koçer et $\mathrm{al}^{6}$ in a single case scenario during their preliminary experience with PHIL. The authors did not report any technical complications or adverse physiologic changes due to the combination of both agents.

Recently, Xu et $\mathrm{al}^{18}$ described an efficient method of combining regular and diluted viscosities of $\mathrm{EVOH}$ to treat cerebral AVMs. The proposed method consists of initial embolization with regular-viscosity formulations of $\mathrm{EVOH}$, followed by injection of a lower viscosity mixture of $1.5 \mathrm{~mL}$ of EVOH diluted with $0.5 \mathrm{~mL}$ of DMSO through the same microcatheter. The technique was performed in 15 patients with a reported average of $90 \%$ (range, 55\%-100\%) estimated size reduction. In 6 patients, the AVMs were completely obliterated. Control over the proximal reflux and success of the technique was achieved in $80 \%$ of the cases.

In regards to fluid resistance to deformation, extra-low-viscosity formulations of the established nonadhesive LEAs, PHIL 25\% low viscosity and SQUID 12. As mentioned above, of the commercially available precipitating, nonadhesive embolic agents, SQUID 12 is the only extra-low-viscosity version so far with a growing body of literature supporting the effectiveness of this agent when used for embolization of vascular malformations. ${ }^{19,20}$ Several experimental studies investigated the improved features of PHIL 25\% low-viscosity and SQUID 12 formulations. ${ }^{21,22}$ Both reports confirmed the embolization extent and the distal penetration to be higher for the low-viscosity agents compared with the standard ones. All investigated embolic agents demonstrated optimal flow control and a significantly lower amount of reflux. This aspect can be highly relevant in clinical practice. However, the authors suggested conceivable drawbacks of extralow-viscosity LEAs in terms of early distal embolization, thus increasing the risk of premature obliteration of the draining veins or unintentional embolization of vital vasculature. Nevertheless, the yielded technical results suggest that for selected types of vascular lesions, the low-viscosity LEAs can be the preferred agents over the currently available standard-viscosity LEAs (eg, Onyx 18, SQUID 18, Menox 18, and PHIL 25\%).

Several antireflux modifications are being developed to gain better control over the flow during embolization. The so-called pressure-cooker technique is designed to create an antireflux plug by trapping the detachable part of the microcatheter used for Onyx delivery via coils and glue. Successful execution of this method is reported to obtain a better forceful and controlled EVOH embolization.

The emergence of DMSO-compatible balloons provides better reflux control and improved flow conditions when using nonadhesive LEAs, allowing the agents to travel more distally. ${ }^{23}$ Difficulties in navigation in distal arterial sites and the risks of vessel rupture due to balloon overinflation exist in this technique. ${ }^{24}$ Using double-lumen balloon catheters with even smaller diameters may reduce the technical complications and increase the embolization rates. ${ }^{25}$ In this context, commercially available prototypes of extra-small balloon microcatheters can be extremely advantageous and make untreatable lesions curable.
Our initial experience with combining nonadhesive liquid embolic agents with different viscosities for AVM treatment yielded promising results. The average estimated size reduction of the nidus was $85 \%$. Total endovascular obliteration in 1 endovascular session was achieved in more than half of the included patients (10/16). In our initial-but-limited experience with this method, we did not observe an increased risk of inadequate nidal embolization, retraction failures, or any occasions in which the used LEAs precipitated and blocked the microcatheter.

\section{Limitations}

Despite being the largest clinical study of the treatment of cerebral AVMs with combined liquid embolic agents delivered via the same microcatheter reported to date, our study has several important limitations. First, this is a single-center experience, and the technical results are limited by the authors' individual techniques and experiences. Second, the sample is relatively small. Thus, the results of our study should be interpreted with caution because they may not be widely applicable to general practice. Last, pharmacoeconomics in developing countries holds promise for patients with certain neurovascular diseases, particularly those who require multiple treatment modalities. Unfortunately, this issue was the only reason for particularly choosing Menox 18 over the other available EVOHs. The same is true for the use of PHIL 30\% for the initial plug formation followed by further embolization with PHIL 25\%.

\section{CONCLUSIONS}

Combined nonadhesive liquid embolic agents delivered via the same microcatheter have the potential to facilitate and increase the success rate of endovascular embolization of cerebral AVMs while carrying risks similar to those of other available approaches. Due to the relatively small size of our study, further investigations are required to validate the safety and the efficacy of the method.

\section{REFERENCES}

1. Potts MB, Zumofen DW, Raz E, et al. Curing arteriovenous malformations using embolization. Neurosurg Focus 2014;37:E19 CrossRef Medline

2. Loh Y, Duckwiler GR; Onyx Trial Investigators. A prospective, multicenter, randomized trial of the Onyx liquid embolic system and N-butyl cyanoacrylate embolization of cerebral arteriovenous malformations. J Neurosurg 2010;113:733-41 CrossRef Medline

3. Samaniego EA, Kalousek V, Abdo G, et al. Preliminary experience with Precipitating Hydrophobic Injectable Liquid (PHIL) in treating cerebral AVMs. J Neurointerv Surg 2016;8:1253-55 CrossRef Medline

4. Akmangit I, Daglioglu E, Kaya T, et al. Preliminary experience with Squid: a new liquid embolizing agent for AVM, AV fistulas and tumors. Turk Neurosurg 2014;24:565-70 CrossRef Medline

5. Pedicelli A, Lozupone E, Valente I, et al. Pre-operative direct puncture embolization of head and neck hypervascular tumors using SQUID 12. Interv Neuroradiol 2019 Dec 19. [Epub ahead of print] CrossRef Medline

6. Koçer N, Hanımoğlu H, Batur S, et al. Preliminary experience with precipitating hydrophobic injectable liquid in brain arteriovenous malformations. Diagn Interv Radiology 2016;22:184-89 CrossRef Medline

AJNR Am J Neuroradiol 41:681-86 Apr 2020 www.ajnr.org 
7. Chapot R, Stracke P, Velasco A, et al. The pressure-cooker technique for the treatment of brain AVMs. J Neuroradiol 2014;41:87-91 CrossRef Medline

8. Pasqualin A, Cioffi F, Barone G, et al. The relevance of anatomic and hemodynamic factors to a classification of cerebral arteriovenous malformations. Neurosurgery 1991;28:370-79 CrossRef Medline

9. Davies JM, Yanamadala V, Lawton MT. Comparative effectiveness of treatments for cerebral arteriovenous malformations: trends in nationwide outcomes from 2000 to 2009. Neurosurg Focus 2012;33: E11 CrossRef Medline

10. Vaidya S, Tozer K, Chen J. An overview of embolic agents. Semin Intervent Radiol 2008;25:204-15 CrossRef Medline

11. Brzozowski K, Ziecina P, Piasecki P, et al. Effectiveness of ONYX liquid embolic agent in endovascular treatment of cerebral arteriovenous malformations - own experience. Eur Congr Radiol 2011

12. Ayad M, Eskioglu E, Mericle RA. Onyx $\mathbf{x}^{\oplus}$ a unique neuroembolic agent. Expert Rev Med Devices 2006;3:705-15 CrossRef Medline

13. Crowley RW, Ducruet AF, McDougall CG, et al. Endovascular advances for brain arteriovenous malformations. Neurosurgery 2014;74:S74-82 CrossRef Medline

14. Lv X, Wu Z, Li Y. Arteriovenous malformation in the brain: a theoretical study explaining the behavior of liquid embolic agents during endovascular treatment. Neuroradiol J 2013;26:661-68 CrossRef Medline

15. Vollherbst DF, Sommer CM, Ulfert C, et al. Liquid embolic agents for endovascular embolization: evaluation of an established (Onyx) and a novel (PHIL) embolic agent in an in vitro AVM model. AJNR Am J Neuroradiol 2017;38:1377-82 CrossRef Medline

16. Sirakov S, Sirakov A, Minkin K, et al. Initial experience with the new ethylene vinyl alcohol copolymer based liquid embolic agent Menox in the endovascular treatment of cerebral arteriovenous malformations. J Neurointerv Surg 2019;11:1040-44 CrossRef Medline
17. Sirakov SS, Sirakov A, Minkin K, et al. Initial experience with precipitating hydrophobic injectable liquid in cerebral arteriovenous malformations. Interv Neuroradiol 2019;25:58-65 CrossRef Medline

18. Xu H, Wang L, Guan S, et al. Embolization of brain arteriovenous malformations with the diluted Onyx technique: initial experience. Neuroradiology 2019;61:471-78 CrossRef Medline

19. Gioppo A, Faragò G, Caldiera V, et al. Medial tentorial dural arteriovenous fistula embolization: single experience with embolic liquid polymer SQUID and review of the literature. World Neurosurg 2017;107:1050.e1-e7 CrossRef Medline

20. Erbahceci Salik A, Islim F, Akgul A, et al. Concomitant transarterial and transvenous embolization of a pelvic arteriovenous malformation using a new liquid embolic agent, Squid-12 and detachable coils. Case Rep Vasc Med 2014;2014:972870-75 CrossRef Medline

21. Vollherbst DF, Otto R, Hantz M, et al. Investigation of a new version of the liquid embolic agent PHIL with extra-low-viscosity in an endovascular embolization model. AJNR Am J Neuroradiol 2018;39:1696-1702 CrossRef Medline

22. Samaniego EA, Derdeyn CP, Hayakawa $M$, et al. In vivo evaluation of the new PHIL low viscosity in a swine rete mirabile model. Interv Neuroradiol 2018;24:706-12 CrossRef Medline

23. Spiotta AM, James RF, Lowe SR, et al. Balloon-augmented Onyx embolization of cerebral arteriovenous malformations using a dual-lumen balloon: a multicenter experience. J Neurointerv Surg 2015;7:721-27 CrossRef Medline

24. Jagadeesan BD, Grigoryan M, Hassan AE, et al. Endovascular balloon-assisted embolization of intracranial and cervical arteriovenous malformations using dual-lumen coaxial balloon microcatheters and Onyx: initial experience. Oper Neurosurg 2013;73:ons238-43 CrossRef Medline

25. Vollherbst DF, Otto R, Do TD, et al. Extra-small dual-lumen microballoon catheters can improve endovascular embolization: an experimental in vivo and in vitro study. J Neurointerv Surg 2018;10:1092-96 CrossRef Medline 